\section{Association of tumour necrosis factor alpha -308 gene polymorphism with primary open- angle glaucoma in Chinese}

H-J Lin ${ }^{1}$, F-J Tsai ${ }^{2}$ W-C Chen², Y-R Shi ${ }^{2}$, Y Hsu ${ }^{2}$ and S-W Tsai ${ }^{3}$

Keywords: tumour necrosis factor; genetic polymorphism; glaucoma

Introduction

Glaucoma is the secondary leading cause of blindness worldwide. ${ }^{1}$ It is a heterogeneous ocular disease characterized by optic neuropathy and a progressive loss of the visual field. $^{2,3}$ Primary open-angle glaucoma (POAG) is the most common form of glaucoma ${ }^{3-5}$ characterized by elevated intraocular pressure and an open anterior chamber angle.

Environmental factors do not seem to play a definitive role in glaucoma and therefore genetic influences are responsible for the aetiology of POAG. A family history of glaucoma is one of the major risk factors for the disease, as a substantial subset of cases of POAG is hereditary. ${ }^{6-9}$ The relationships between glaucoma and genetic polymorphisms, although not traditionally perceived as being causally related, have been highly suspected recently. ${ }^{10}$ The role of the immune system in glaucoma is likely one of surveillance, in which signal pathways of the immune system regulate cell death in response to conditions that stress retinal neurons in glaucoma. These might include mechanical stress from high intraocular pressure, ischaemia, and excessive excitatory amino acid.

Tissue constitutive expression of tumour necrosis factor receptor-1 (TNF-R1) in the vessels of the optic nerve heads has been demonstrated, although there was no positive labelling for tumour necrosis factor alpha (TNF $\alpha){ }^{11}$ However, in the glaucomatous optic nerve heads, the expressions of both TNF $\alpha$ and TNF$\mathrm{R}$ are apparently upregulated. The same
${ }^{1}$ Department of Ophthalmology China Medical College Hospital

Taichung, Taiwan

${ }^{2}$ Department of Medical Genetics and Pediatrics China Medical College Hospital

Taichung, Taiwan

${ }^{3}$ Department of Occupational Safety and Health \& Institute of Environmental Medicine China Medical College Taichung, Taiwan

Correspondence: F-J Tsai

Department of Medical Genetics and Pediatrics China Medical College Hospital Yuh-Der Road Taichung 404, Taiwan Tel: +886 422052121 ext 1566 Fax: +886 422033295 E-mail: d0704@ www.cmch.org.tw

Received: 12 November 2001

Accepted in revised form: 28 March 2002 
researchers believe that TNF $\alpha$ contributes to the progression of optic nerve degeneration in glaucoma by both a direct effect on the axons of the retinal ganglion cells and by inducing NOS-2 in astrocytes. ${ }^{11}$ Besides, glial cells have been found to secrete TNF $\alpha$ as well as other noxious agents, such as nitric oxide, after exposure to stress. ${ }^{12}$ Furthermore, it has been noted that retinal ganglion cell apoptosis can be attenuated by neutralized antibodies against TNF $\alpha^{12} \mathrm{TNF} \alpha$ has been shown to be a component of astroglial activation in glaucomatous optic nerve heads. The expression of these proteins may play a role in the progression of glaucomatous optic neuropathy. ${ }^{13}$

Cytokines are molecules involved in signalling between cells during immune response, and TNF $\alpha$ is one such protein. An increasingly well-defined chain of protein-protein recognition events ties the binding of a cytokine at the cell surface, initiating a downstream signalling cascade thereby inducing the actions of diverse transcription factors inside the nucleus. TNF $\alpha$ activates members of the MAP kinese family, resulting in increased binding of the transcription factors AP-1, $\mathrm{NF}_{\kappa} \mathrm{B}$, and NFIL- 6 to DNA. ${ }^{14}$ The variation of transcriptive states results in a change in protein expression.

The TNF $\alpha$ gene encodes proteins that are pleiotropic in appearance. Recently, several genetic polymorphisms have been described in the human TNF $\alpha$ promoter. ${ }^{15,16}$ Biallelic $\mathrm{G}$ to A polymorphism, 308 nucleotides upstream from the transcription initiation site in the TNF promoter, is associated with elevated TNF levels, disease susceptibilities, and poor prognosis in several diseases. ${ }^{16}$ The existence of different TNF $\alpha$ alleles is related to different levels of TNF $\alpha$. In this study, we tried to evaluate whether the TNF $\alpha 308$ polymorphism is a useful marker for predicting the susceptibility of POAG.

\section{Materials and methods}

From May 2000 to July 2000 we recruited POAG patients from the Department of Ophthalmology at the China Medical College Hospital. All patients in this study received serial ophthalmic examinations, including IOP, visual acuity, automated perimetry, gonioscopy, optic disc examination, and retinal examination. Patients with ocular diseases other than POAG were excluded from our study. The volunteers in the control group were examined by the same ophthalmologist. The volunteers were healthy people collected when they attended their routine healthy examination. If there were any doubts regarding the patients' eye diseases, they were excluded from the study. Patients included in this study were POAG patients who were required to fulfil one criterion from both the visual field and the optic nerve categories.

\section{Visual field criteria}

(1) At least two abnormal visual field tests by Humphrey automated perimetry, as defined by computer-based objective criteria.

(2) The presence of one or more absolute defects in the central visual field $30^{\circ}$, with ophthalmologic interpretation as glaucomatous visual field loss.

Optic disc criteria (optic disc damage present in fundus photographs)

(1) Either a horizontal or vertical cup-to-disc ratio of 0.6 or more.

(2) The narrowest remaining neuroretinal rim was $20 \%$ or fewer disc diameters.

\section{Ophthalmologic criteria}

Patients with other possible causes for disc and field changes other than POAG were excluded.

This study was carried out with approval from the Human Study Committee of the China Medical College Hospital. Informed consent was obtained from all patients who participated in this study. The genomic DNA was prepared from peripheral blood using a Genomaker reagent kit (Blossom, Taiwan).

The loci of the TNF $\alpha$ gene were studied as previously described by Galbraith and Pendey. ${ }^{15}$ It involved a G to A transition at position -308 in the $5^{\prime}$-flanking promoter region of the TNF $\alpha$ gene. The region was amplified by polymerase chain reaction (PCR) using a Gene Amp PCR kit (Perkin-Elmer, Norwak, CT, USA). The sequences of the primers were as follows: $5^{\prime}$ -

AGGCAATAGGTTTTGAGGGCCAT- ${ }^{\prime}$ and $5^{\prime}$ ACACTCCCCATCCTCCCGGCT-3'. About $50 \mathrm{ng}$ of genomic DNA was mixed with 20 pmol of each PCR primer in a total volume of $25 \mu \mathrm{l}$ containing $10 \mathrm{mM}$ Tris$\mathrm{HCl}, \mathrm{pH} 8.3,50 \mathrm{mM} \mathrm{KCl}, 2.0 \mathrm{mM} \mathrm{MgCl}$, as well as $0.2 \mathrm{mM}$ of each deoxyribonucleotide triphosphate, and 1 unit of Amplitaq DNA polymerase (Perkin-Elmer). PCR was programmed as follows: 35 cycles at $95^{\circ} \mathrm{C}$ for $15 \mathrm{~s}$ followed by 35 cycles at $60^{\circ} \mathrm{C}$ for $30 \mathrm{~s}$.

The polymorphism was analysed by PCR amplification followed by $\mathrm{NcoI}$ restriction analysis. ${ }^{15}$ The products were analysed by electrophoresis on agarose gel and each allele was recognized according to its size. Restriction enzyme digestion was performed with $\mathrm{NcoI}$ and subsequent electrophoresis on a $5-8 \%$ polyacrylamide gel. The molecular analyses of patients and controls are performed in the same laboratory at the same time and the gels are inspected by investigators who are masked to the clinical phenotype of the individuals being studied.

Statistical analysis for the relative risk of TNF $\alpha$ in the control and POAG groups was compared by the $\chi^{2}$ test. Results were considered statistically significant when the probability of findings occurring by chance was less than 
5\% $(P<0.05)$. The allelic frequencies were rechecked by odds ratio with $95 \%$ confidence intervals (CI).

\section{Results}

A total of 103 healthy volunteers (55 males and 48 females) and 60 POAG patients ( 30 males and 30 females) were enrolled in this study. The volunteers ranged in age from 55 to 70 years (mean 50 years) and were free from ophthalmic diseases. The POAG patients ranged in age from 20 to 70 years (mean 55 years) and all were unrelated. Patients with ocular diseases other than POAG were excluded from our study. Patients were followed up between 2 and 8 years (mean 5 years). Ten of the patients had received trabeculectomy and two of the 10 patients received trabeculectomy twice from different sites. Of the POAG patients, 50 were prescribed antiglaucoma drugs. Each patient used 1.3 types of antiglaucomatous drugs on an average. Nine patients did not need drugs to control IOP after trabeculectomy.

Homozygote $\mathrm{G}^{-308}$ allele showed two fragments of 97 and $20 \mathrm{bp}$. Homozygote $\mathrm{A}^{-308}$ was undigested and resulted in a single band of $117 \mathrm{bp}$. Heterozygote $A / G$ was detected by the presence of all three fragments (Figure 1). The frequencies of the genotypes in the control and POAG patient groups are shown in Table 1. Using the $\chi^{2}$ test, we compared the distribution of the TNF $\alpha$ -308 polymorphism. There were significant differences between the two groups $(P=0.00015885 ; P<0.05)$. The distribution in the control group revealed $6.8 \% \mathrm{~A}^{-308}$ allele homozygote, $29.1 \%$ heterozygote, and $64.1 \% \mathrm{G}^{-308}$ allele homozygote. The genotype distribution in the POAG group revealed $31.7 \% \mathrm{~A}^{-308}$ allele homozygote, $21.7 \%$ heterozygote, and $46.6 \% \mathrm{G}^{-308}$ homozygote. The allelic frequencies in the POAG group were $42.5 \% \mathrm{~A}$ and $57.5 \% \mathrm{G}$. The allelic frequencies in the control group were $21.4 \% \mathrm{~A}$ and $78.6 \% \mathrm{G}$. The odds ratio of the $\mathrm{A}^{-308}$ allele was 2.721 (95\% CI: 1.66-4.45) in comparison with the A

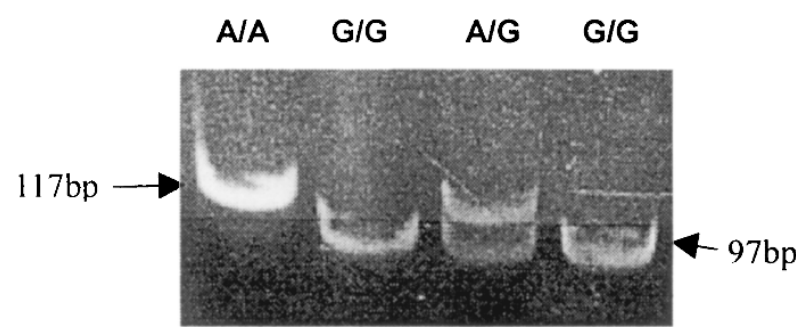

Figure 1 Genotypes of TNF $\alpha-308$ panel shown on a 3\% agarose gel stained with ethidium bromide after PCR amplification. Homozygote $\mathrm{G}^{-308}$ allele has two fragments: 97 and $20 \mathrm{bp}$ (lines 2 and 4). Homozygote $\mathrm{A}^{-308}$ allele is an undigested single band: $117 \mathrm{bp}$ (line 1). Heterozygote $\mathrm{A} / \mathrm{G}$ includes all three fragments (line 3) and $G$ alleles in POAG patients (Table 2). The frequencies of allele A were significantly higher in the POAG group than in the control group. When we set the odds ratio of the heterozygote as ' 1 ', the odds ratio of allele A homozygote was determined to be 6.263 (95\% CI: 2.521$15.559)$, and the odds ratio of allele $\mathrm{G}$ homozygote was 0.979 (95\% CI: 0.424-2.257) (Table 1). The A/A homozygote was significantly higher in the POAG group.

We also calculated 'power' for a test of the null hypothesis by SPSS ${ }^{\circledR}$. There is a power of $55 \%$ to yield a statistically significant result in this sample size. An ageadjusted analysis for the A allele also revealed a significant difference between the two groups. This meant that age did not have an influence on the result.

\section{Discussion}

Wax ${ }^{10}$ brought out that glaucomatous optic neuropathy may occur directly by autoantibodies or indirectly by way of a 'mimicry' autoimmune response to a sensitizing antigen. ${ }^{10}$ The immune system acts as an arbiter to help determine whether a neuronal cell confronting stress will ultimately survive or be sacrificed to injury.

The $\mathrm{A}^{-308}$ allele of the TNF $\alpha$ promoter affects the binding of transcription factors and increases transcription promoter activity, which may further alter the TNF production, the immune response, and susceptibility to certain autoimmune, infectious, and malignant diseases. ${ }^{17}$ Besides, the $\mathrm{A}^{-308}$ allele may inhibit repressors of transcription. ${ }^{18}$ The TNF $\alpha$ promoter polymorphism may also be functionally silent or have selectable effects only when there is linkage with selectable HLA alleles. ${ }^{18,19}$ The presence of a G to A polymorphism at position 308 of the TNF $\alpha$ promoter gene could increase transcription six- to seven-fold. ${ }^{20}$ It is obvious that the variable polymorphisms that lie within the promoter region of the TNF $\alpha$ locus make it a likely candidate for playing a regulatory role in disease.

In our study, owing to the frequency of the $-308 \mathrm{~A}$ allele noted in POAG patients, we have to consider the possibility that a functional distinction between $\mathrm{A}^{-328}$ and $\mathrm{G}^{-308}$ becomes prominent upon a physiologic TNFinducing stimulus that is specific for POAG. Such a stimulus may be different from the standard in vitro TNFinducing agents, and variations in the genes coding for TNF have been found to affect the production of relevant cytokines. ${ }^{11}$ However, we cannot exclude $\mathrm{A}^{-308}$ allele as a genetic marker for other polymorphisms that have functional implications for TNF gene expression. Consequently, $\mathrm{A}^{-308}$ may influence the susceptibility of POAG by way of immune effects. It may be involved in the formation of the disease, through a complex pathway, ${ }^{15}$ such as a change from signal transduction 
Table 1 Distribution of TNF $\alpha$ genotype among glaucoma patients and healthy control subjects

\begin{tabular}{lcccc}
\hline & $A / A(\%)$ & $A / G(\%)$ & $G / G(\%)$ & $P$ value \\
\hline POAG & $19(31.7)$ & $13(21.7)$ & $28(46.6)$ & 0.0015885 \\
Control & $7(6.8)$ & $30(29.1)$ & $66(64.1)$ & $94(57.7)$ \\
Total & $26(16.0)$ & $43(26.4)$ & 0.979 & \\
Odds ratio & 6.263 & 1 & $(10.424,2.257)$ & \\
$(95 \% \mathrm{CI})$ & $(2.521,15.5569)$ & & & \\
\hline
\end{tabular}

Table 2 Allelic frequencies in healthy subjects and POAG patients

\begin{tabular}{lcc}
\hline & $A(\%)$ & $G(\%)$ \\
\hline POAG & 42.5 & 57.5 \\
Control group & 21.4 & 78.6 \\
\hline
\end{tabular}

Note: Odds ratio of allele A is 2.721 of POAG group (95\% CI: 1.66-4.45).

between cells and then change the function of transformation.

In this study we noted that allele A of TNF $\alpha-308$ polymorphism is a useful marker for predicting the susceptibility of Chinese POAG patients. These results would support a mechanism involving the immune response in glaucomatous damage, and this may provide a novel therapeutic target for neuroprotection in the treatment of glaucomatous optic neuropathy. An understanding of the genetic and immune role in POAG is an important way to design new treatment for glaucoma.

\section{References}

1 Van Buskirk EM. Glaucoma lexicon. Am J Ophthalmol 1990; 108: 730-731.

2 Quigley HA. Number of people with glaucoma worldwide. Br J Ophthalmol 1996; 80: 389-393.

3 Anderson DR. Glaucoma: the damage caused by pressure. The XLVI Edward Jackson Memorial Lecture. Am J Ophthalmol 1989; 108: 485-495.

4 Hoskin HJ, Kass M. Primary open-angle glaucoma. In: Klein EA (ed). Becker-Shaffer's Diagnosis and Therapy of the Glaucomas, 6th edn. CV Mosby: St Louis, 1989, pp 277-307.

5 Tielsch J, Katz J, Singh K et al. A population-based evaluation of glaucoma screening: the Baltimore Eye Survey. Am J Epidemiol 1991; 134: 1102-1110.

6 Courtney RH, Hill EH. Hereditary juvenile glaucoma simplex. J Am Med Assoc 1931; 97: 1602-1609.

7 Francois J. Genetics and primary open angle glaucoma. Am J Ophthalmol 1966; 61: 652-665.

8 Lichter RP. Genetic clues to glaucoma's secrets. The L. Edward Jackson Memorial Lecture: part 2. Am J Ophthalmol 1994; 117: 706-726.
9 Beckman L, Frohlander N. Heterozygosity effects in studies of genetic markers and disease. Hum Hered 1990; 40: 322-329.

10 Wax MB. Is there a role for the immune system in glaucomatous optic neuropathy? Curr Opin Ophthalmol 2000; 11: 145-150.

11 Yuan L, Neufeld AH. Tumor necrosis factor-alpha: a potentially neurodestructive cytokine produced by glia in the human glaucomatous optic nerve head. Glia 2000; 32: $42-50$.

12 Tezel G, Wax MB. Increased production of tumor necrosis factor-alpha by glia cell exposed to simulated ischemia or elevated hydrostatic pressure induces apoptosis in cocultured retinal ganglion cells. J Neurosci 2000; 20 : 8693-8700.

13 Yan X, Tezel G, Wax MB, Edward DP. Matrix metalloproteinase and tumor necrosis factor $\alpha$ in glaucomatous optic nerve head. Arch Ophthalmol 2000; 118: 666-673.

14 Roitt I, Brostoff J, Male D. Immunology. In: Graham R, Frances B (eds). Cell-mediated Immune Reactions, 5th edn. CV Mosby: St Louis, 2000, pp 123-125.

15 Galbraith GH, Pendey JP. Tumor necrosis factor alpha (TNFA) gene polymorphism in alopecia areata. Hum Genet 1995; 96: 433-436.

16 Patino GA, Sotillo PE, Modesto C, Sierrasesumaga L. Analysis of human tumour necrosis factor alpha (TNF $\alpha$ ) gene promoter polymorphisms in children with bone cancer. J Med Genet 2000; 37: 789-791.

17 Abraham LJ, Kroeger KM. Impact of the -308 TNF promoter polymorphism on the transcriptional regulation of the TNF gene: relevance to disease. J Leukon Biol 1999; 66 562-566.

18 Wilson AG, Symons JA, McDowell YL, Giovane FS, di Duff GW. Effects of a tumor necrosis factor (TNF $\alpha$ ) promoter base transition on transcriptional activity. Br J Rheumatol 1994; 33: 89.

19 Allen RD. Polymorphism of the human TNF-alpha promoter - random variation or functional diversity? Mol Immunol 1999; 36(15-16): 1017-1027.

20 Agarwal P, Oldenburg Mc, Czarmeski JE et al. Comparison study for identifying promoter allelic polymorphism in interleukin 10 and tumor necrosis factor alpha genes. Diagn Mol Pathol 2000; 9: 158-164. 